\title{
DESIGNING COLLABORATIVE LEARNING ENVIRONMENT IN TRANSLATOR TRAINING: AN EMPIRICAL RESEARCH
}

\section{ÖZGE BAYRAKTAR-ÖZER}

At1lim University

ozge.ozer@atilim.edu.tr

\section{GÖKÇEN HASTÜRKO $\breve{G L U}$}

Atılım University

gokcen.hasturkoglu@atilim.edu.tr

\begin{abstract}
The present study aims to investigate the efficacy of the collaborative learning method on the translation skills of students at the undergraduate level through a new model developed by the researchers. To this end, a pre-/post-test control group research design was followed to obtain empirical results in the translation of medical texts. The study group consisted of 60 undergraduate translation students in Turkey. Thirty students in the control group were instructed by using conventional training methods and each student worked individually. The completed translation was then evaluated by the instructor, as commonly applied in undergraduate translation programmes. The other 30 subjects in the experimental group were instructed through the collaborative learning method. The students participated in teamwork and undertook various roles such as terminologists, translators, proof-readers, and peer editors to check the final work. At the end of the three-week training, the difference between the translation performance scores of the two groups was found statistically significant in favour of the experimental group. The findings demonstrate the significant contribution of the collaborative learning method to the undergraduate students as this method provides them with an environment to improve the necessary translation skills for their future careers in terms of adopting different roles other than translators.
\end{abstract}

Keywords: collaborative learning, translator training, translation skills, teamwork, undergraduate translation pedagogy

\section{Introduction}

Trainers in undergraduate translation and interpretation departments require to apply multi-faceted approaches, one of which is collaborative or cooperative techniques in translation classrooms, because the responsibility of translators is not only to transfer the meaning of a source text into a target text, but also assuming the role of terminologists, cultural transmitters, linguists, editors, and even authors. 
Traditionally, instructors tend to apply conventional teaching methods by providing students with a source text to be translated, and evaluating the translations of students in terms of accuracy. According to Kiraly, such traditional learning environments involve a didactic performance by a teacher, who believes that she is the only one with the correct translation. Here, the roles of the instructor are to select and bring the source text into the classroom, make students translate the texts either at home or in the class alone, listen to translations from different students and correct the errors orally, and assess the knowledge of students through an exam at the end of the semester. In this way, students translate the source texts alone at home or in class, read aloud the translations in front of the rest of the class, change their translations in accordance with the corrections of the instructor, and take the exam in order to demonstrate the knowledge they gained in the course (1997: 152). In this process, the only aim for students is to achieve translations that are approved to be accurate by the instructor.

This approach has been criticized by many scholars as it puts the instructor at the centre and makes students passive listeners or learners. As Sorvali (1998) states, evaluating translation in terms of accuracy is nothing but a form of language testing, and as such, should not be the only aim of the trainer in translation classes. Similarly, González Davies (2004) asserts that traditional translation classrooms are usually teacher- and text-centred and writing-based, without the consideration of class dynamics and interaction (qtd. in Melnichuk, Osipova 2017: 26).

Rather than the traditional approach, which involves the dominance of the instructor and the passivity of the students, constructivist approaches to learning and teaching have been used especially after the work of Piaget (1954/1955/1970; Piaget and Inhelder 1971) and Vygotsky (1962/1978) Their constructivist view of learning and teaching argues the following:

In this view, learning is a constructive process in which the learner is building an internal illustration of knowledge, a personal interpretation of experience.... Learning is an active process in which meaning is developed on the basis of experience. Conceptual growth comes from the sharing of multiple perspectives and the simultaneous changing of our internal representations in response to those perspectives as well as through cumulative experience. (Bednar et al. 1992: 21)

Over the last decade, the importance of creating a constructivist environment in translation classrooms has been foregrounded, and primarily, collaborative learning has been discussed by a vast number of researchers. In theoretical and applied studies, it has been emphasized that in collaborative learning environments, students can actively participate in classroom activities, achieve deep learning, and get involved in real-life tasks. The collaborative learning approach calls for interaction and cooperation of learners and instructors pointing to the significance of such methods as teamwork in translation courses, and that the gap between real-life and the courses taught at universities to be fulfilled through such tendencies.

Within the framework of collaborative approaches to translator training, Barros (2011) conducted a qualitative study to observe the merits of collaborative 
learning and obtained the comments of the students on teamwork at the Translation and Interpreting faculties in Spain. It was observed that a high percentage of students ( 45.5 per cent) are aware of the importance of interpersonal competence in their translator training. In a recent study, Al-Shehari (2017) investigated the contribution of collaborative learning by Wikipedia to teaching translation through observation of the actions and the comments given by students and other participants in regard to various Wikipedia pages. The results could not be used to improve the quality of students' translations, as no satisfactory feedback was given by the specialists who visited the translated web pages. In another study that shed light on the implementation of collaborative learning in translator training, Gonzalez and Diaz (2015) found considerable improvements in translation competences of the students trained with the project-based learning method. In another example, Moghaddas and Khoshsaligheh (2019) examined the impact of the collaborative learning method on critical thinking skills, translation quality as well as the attitudes of the students towards teamwork performance. The empirical data suggested that this is an effective method in translator training since improvement is found in all the stated areas.

In line with the emphasis on the importance of collaborative learning in the literature, this study attempts to offer empirical evidence for the effect of collaborative learning in translator training, and to test the efficacy of the collaborative translation task method developed by the researchers.

To this end, the first section of the study is dedicated to the theoretical background on translation competence and collaborative learning in translation pedagogy, as well as the statement of the aim and hypothesis of the study. The second section dwells upon the methodology, in which the research design, participants, materials as pre-/post-tests, and procedure of the training are explained. The findings and result of the study are presented quantitatively and qualitatively in the third section. Finally, section four concludes the paper.

\subsection{Theoretical Background: Translation Competence and Collaborative Learning in Translation Pedagogy}

The complex and versatile nature of translation makes it difficult to provide a precise definition of translation competence, which still remains an ambiguous term. Pym (2003) defines translation as "a process of producing and selecting between hypotheses" (492), and offers a minimalist approach to define competence to replace the multicomponent model. Similarly enough, Pietrzak (2015) agrees that the boundaries of translation competence is hard to drawn and aims to examine the concept of translation competence in relation to various theoretical approaches (317). Although scholars and trainers have not yet reached a consensus on the definitions and the precise criteria for translation competence, one of the most comprehensive definitions is put forth by PACTE as "the underlying system of knowledge and skills needed to be able to translate" (2000: 100). The exploration and statement of such knowledge and skills assumed to be needed by a competent translator is another issue that has not been agreed upon so far. In this direction, Orozco and Albir highlight the lack of a commonly 
acknowledged model for translation competence (2002: 375). In addition to the obvious prerequisite of a good command of source and target languages, there are some other frequently mentioned qualifications for a quality translation, such as the subject area knowledge (Bell 1991; Neubert 1994), the knowledge of cultural elements (Hewson 1995; Kiraly 1995) and the ability to work professionally (Hurtado Albir 1996; Kiraly 2012; PACTE 2003). With these in mind, linguistic, cultural, textual and professional competence can be regarded as the main components of translation competence.

Translator training programmes are observed to lay the ground for improving the linguistic skills of the students and raising their awareness towards both cultures, mostly by means of offering a sufficient number of textual exercises to the students. On the other hand, these exercises of translation tasks are mostly carried out by students individually, although in a professional environment of translation business, the responsibility of the translator to produce a text is not a solely individual assignment, but rather an interaction shared by "networks of contacts, clients and collaborators" as Pym (2003: 493) posits. In order to improve the professional skills of the students by presenting the qualifications expected by the translation business, as well as to build a more sound learning environment, it is assumed that such conventional training methods need to be modified to include tasks such as teamwork, division of labour, brainstorming during the translation process, giving and receiving feedback on the translation product, and so on. It is in the collaborative learning environments that translation students can act cooperatively and efficiently.

Collaborative learning was defined by Johnson and Johnson (1994: 14) as the "instructional use of small teams so that students work together to maximise their own and each other's learning". Similarly, Kiraly (2000: 36), the first author to develop a methodology for collaborative learning, claimed: "True collaborative learning does not mean simply dividing up the work on a task, a mere division of labour. It is instead the joint accomplishment of a task with the dual learning goals of meaning-making on the part of each individual group member." In the context of translation training, collaborative translation task was defined by O'Brien (2011: 17) as "when two or more agents cooperate in some way to produce a translation". Thus, collaborative learning requires the division of a task among team members and establishing meanings with the other group members to accomplish the aim.

Within the framework of translator training, it is only through collaborative learning methods that translation students develop related competences by gaining real-life experiences. Thus, the collaborative learning approach can be actively used in translation classes since translation today requires not only individual work, but also the ability to confer with others to achieve optimum results.

\subsection{Aim of the Study}

This study aims to elaborate the contribution of collaborative learning tasks to translation skills acquisition and development of translation students by filling the empirical data lacunae in the literature. To serve this purpose, a new collaborative 
learning model was developed by the researchers to be employed in medical translation courses. The study also targets at testing the efficacy of this model on the translation performances of undergraduate students in the medical translation course.

\subsection{Hypothesis}

The primary hypothesis of the study is that the collaborative learning method has a noteworthy contribution to the translation skills of undergraduate students by means of offering an active and real-life learning environment, in which various roles within a translation commission can be experienced by each learner in contrast with the conventional translator training centred on teacher-authority.

Grammar is a system of rules which govern the form of the utterances in a given language. It encompasses both sound and meaning, and includes phonology (how sounds and gestures function together), morphology (the formation and composition of words), and syntax (the formation and composition of phrases and sentences from words).

Linguistic salso includes nonformal approaches to the study of other aspects of human language, such as social, cultural, historical and political factors. The study of cultural discourses and dialects is the domain of sociolinguistics, which looks at the relation between linguistic variation and social structures, as well as that of discourse analysis, which examines the structure of texts and conversations. Research on language through historical and evolutionary linguistics focuses on how languages change, and on the origin and growth of languages, particularly over an extended period of time.

\section{Methodology}

\subsection{Design of the Study}

The purpose of the research is twofold. As for the primary aim, evaluation of the improvement in translation skills of the participants trained with the collaborative learning model, a pre-/post-test control group research design was employed from amongst other quantitative research methods. The scores obtained by the researchers according to the criteria stipulated in the translation evaluation form, otherwise known to the students as feedback sheet, developed by the researchers for the specific use in this study, were the dependent variable of the research, and the attendance to the application of the collaborative learning model was the independent variable. The differences between the pre-/post-test scores of the students were compared statistically in terms of both the overall translation quality and three evaluation categories, accuracy/target language quality, terminology/culture-specific items and grammar/spelling/punctuation. SPSS 25.0 was used for all the statistical analyses in the research. 


\subsection{Participants}

The participants were sixty second- and third-year undergraduate students from the Department of Translation and Interpretation at a university in the spring semester of the 2018-2019 academic year. All the participants volunteered for the research, having successfully completed the ETI 151 Text Studies for Translation, ETI 203 Language Use in Various Fields and ETI 200 Introduction to Translation courses which offered the theoretical background for text types put forth by Reiss $(1981 / 2000)$, textual functions, viable translation approaches for different text types, and fundamental terminology of, inter alia, medical texts. Prior to the onset of the research, all of the participants were lectured on the basic principles of medical translation and given the opportunity to practice on coursebook texts, academic articles, news and popular science texts translations of medicine through traditional training methods. The participants had never been exposed to any collaborative learning task until they participated in this research. To ensure homogeneity between the participants, second- and third-year students were divided equally and randomly into experimental and control groups to investigate the efficacy of collaborative learning on translation performance.

\subsection{Materials}

\subsubsection{Pre/Test and Post/Test Texts}

The participants were provided with a medical coursebook text on the human circulatory system in English to be translated into Turkish for the pre-test. The text included a total of 300 words. For the post-test, another text on the human digestive system of the same length from the same coursebook was used. These texts were selected as main test materials since coursebooks do not contain complex language as academic articles do, but at the same time, they are not written for the layperson. Thus, translation students can easily understand such texts, and they also come across medical terminology and culture-specific items both of which are problematic for translators.

\subsubsection{Translation Evaluation Form}

For the evaluation of the participants' translation quality, a translation evaluation form, including three main categories (accuracy/target language quality, terminology/culture-specific items and grammar/spelling/punctuation) was developed by the researchers. Under each category, certain numerical values are attained for three different levels of translation quality, 5 for 'Excellent', 3 for 'Needs Improvement' and 1 for 'Poor'. Guided explanations are offered under each score and category. The first category, 'Accuracy/Target Language Quality', mainly focuses on faithfulness to the source text message, smooth comprehension, and readability of target text, fulfillment of the textual functions in consideration of text type, genre, target audience, and so on. Achieving accuracy in the target text is one of the main goals in any translation process. Besides, the accurate transfer of the source message with precision is particularly important in medical texts and a quality target language also contributes to the accurate comprehension 
of the translation. Therefore, this category of the form is believed to be crucial for the evaluation of the participants in this study.

The second category, 'Terminology/Culture-Specific Items', is rated according to the proper and accurate transmission of medical terminology and culture-specific items such as units of weight, units of length, and so on. This category is included in the Translation Evaluation Form, since considering the cultural context, detecting the implicit and explicit cultural references, and finding the culturally equivalent term are not separable from language use and among the most important factors that affect translation quality. Likewise, medical terminology is considered to be one of the most problematic issues during the translation act and also in translator training.

The third category 'Grammar/Spelling/Punctuation' tests the presence of any grammar, spelling and punctuation errors. This category is more about observing any possible improvement in the language use of the students, which is targeted by the program curriculum, the given course and the collaborative learning task applied at undergraduate level.

The minimum score and maximum score to be obtained for each completed and submitted translation is 3 and 15, respectively. Expert translator opinions were sought to confirm the content validity of the form. More specifically, two translator-academicians with more than 10 years of experience in translation practice and teaching, reviewed the form. The final version of the form was revised upon their recommendations. They also took part in the study as external raters, along with the researchers for the evaluation of the pre- and post-test scores of the participants to ensure the objectivity of scoring the translation performances. Names of the students and their group (control or experimental) remained unknown to the raters during the evaluation process.

A pilot test was administrated on 20 second- and third-year students to measure the reliability of the translation evaluation form. Accordingly, Cronbach's alpha was found to be 0.71 , indicating acceptability. As stated before, the translation evaluation form was also served as a feedback sheet for the groups of the participants to reflect their comments on the translations of other groups.

\subsection{Procedure}

\subsubsection{Pre-Test}

The participants of the research were initially given a coursebook text on the human circulatory system to translate from English (L2) to Turkish (L1) as a pretest. They were asked to translate the text ( 300 words) within a limited period of time $(1 \mathrm{~h})$ using dictionaries. Each student worked on the terminology and subject matter of the text and translated it individually. At the end of the given time, voluntary students read their translated texts aloud. In the class discussions, problematic parts of the translation and the source text, along with alternative translation solutions were considered and shared among individuals. In the end, the instructor offered the best version of the translation and the students corrected the possible errors of their translations. The translations of the students which 
were completed and corrected in this traditional translator training method, were collected and scored as pre-test according to the translation evaluation form.

\subsubsection{Training}

After the division of the participants into experimental and control groups, collaborative learning tasks were applied within the scope of the translation of medical texts to the experimental group for three weeks, three hours each and nine hours in total. During this period, the students of the experimental group were divided into ten groups of three. In each group, one student assumed the role of terminologist of the given translation task, the second the role of translator and the third, proofreader of the translated text.

In the first week, as the initiator of the translation commission, the instructor uploaded three different texts for each upcoming weeks to Moodle, which is a web-based collaborative learning platform. Throughout the training, the students downloaded these texts and shared tasks of terminology work, translation and proofreading. The completed translation texts were then uploaded to Moodle again. This time, every three members of each group served as editors all together in order to evaluate the translations of other groups, offered feedback according to the feedback sheet, and marked all the errors and improvements required on the text. Each week, the same procedure was followed with a new text to translate and roles interchanged in the group as presented below.

Table 1. Roles undertaken by the students in the first phase, collaborating for translation.

\begin{tabular}{|l|l|l|l|}
\hline Student/Week & $\mathbf{1}^{\text {st }}$ Week & $\mathbf{2}^{\text {nd }}$ Week & $\mathbf{3}^{\text {rd }}$ Week \\
\hline StudentA & Terminologist & Translator & Proofreader \\
\hline StudentB & Translator & Proofreader & Terminologist \\
\hline StudentC & Proofreader & Terminologist & Translator \\
\hline
\end{tabular}

Table 2. Roles undertaken by the students in the second phase, collaborating for editing

\begin{tabular}{|l|l|l|l|}
\hline Student/Week & $\mathbf{1}^{\text {st }}$ Week & $\mathbf{2}^{\text {nd }}$ Week & $\mathbf{3}^{\text {rd }}$ Week \\
\hline $\begin{array}{l}\text { StudentA-B-C } \\
\text { together }\end{array}$ & Editors & Editors & Editors \\
\hline
\end{tabular}

Thus, at the end of three weeks, each group translated three different texts and had experienced working as a terminologist, translator and proofreader. In short, in the first week, the experimental group members undertook different roles, uploaded their work online, downloaded other groups' translations, and served unanimously as editors. Accordingly, it is assumed that the experimental group experienced a real-life working environment of a professional translation task by taking roles not only as a translator but also as terminology specialist, proof-reader and editor.

Meanwhile, the conventional translation teaching method was applied by the same instructor with the same texts of the three translation tasks on the control group, where each student worked individually to complete the translation task of the given texts. As the students completed their translation, voluntary students read their translations aloud, classroom discussions were held on alternatives and the instructor offered the final correct version of the translation while the students fixed their mistakes accordingly. 
In addition, the students of the experimental group actively took part in every phase of the translation process and had to work in tandem with group members to complete the given task and with other group members who offer feedback to their translation as in real-life translation business.

\subsubsection{Post-Test}

At the end of the three weeks, to overcome any possible memorization of the text offered as the pre-test, another text on the human digestive system from the same coursebook administrated to both of the groups as the post-test. The text was modified to ensure the same number of words as the pre-test text ( 300 words). To ensure equal test conditions, the participants of both groups translated the given text within the same period of time as requested in the pre-test. The control group worked individually while the experimental group translated the text collaboratively. The collected translations were then scored by the researchers along with the two external raters based on the translation evaluation form. The mean value was considered as the final score for each student.

The difference between the pre- and post-test results of the experimental group as well as the difference between the post-test results of both experimental and control groups were statistically analysed for the quantitative analysis and discussed within the scope of the theoretical framework.

\section{Findings and results}

For the quantitative analysis of the study, an independent samples t-test was conducted for the statistical analysis of the obtained data to investigate the effectiveness of collaborative learning tasks employed during the translation course by comparing the post-test results of the control and the experimental group. Furthermore, a paired samples t-test was employed to statistically analyse the improvement in the scores of the subjects, who were exposed to the collaborative learning task (the experimental group) by comparing their pre- and post-test results.

Table 3. Descriptive Statistics of the Pre-Test and Post-Test Results for the Control and Experimental Groups

\begin{tabular}{|l|l|l|l|}
\hline & N & Mean & Std. Deviation \\
\hline $\begin{array}{l}\text { Pre-Test Control } \\
\text { Group }\end{array}$ & 30 & 5.00 & 1.49 \\
\hline $\begin{array}{l}\text { Post-Test Control } \\
\text { Group }\end{array}$ & 30 & 5.07 & 1.80 \\
\hline $\begin{array}{l}\text { Pre-Test } \\
\text { Experimental } \\
\text { Group }\end{array}$ & 30 & 4.93 & 1.53 \\
\hline $\begin{array}{l}\text { Post-Test } \\
\text { Experimental } \\
\text { Group }\end{array}$ & 30 & 13.53 & 1.38 \\
\hline
\end{tabular}

The mean values for the pre-test scores were 5.00 and 4.93 for the control and the experimental group, respectively. In both groups, the mean values increased to 
5.07 for the control group and to 13.53 for the experimental group, as presented in Table 3.

Table 4. Independent Samples T-Test Results

\begin{tabular}{|l|l|l|l|l|l|l|}
\hline Test & Group & $\mathbf{N}$ & Mean & $\begin{array}{l}\text { Std. } \\
\text { Deviation }\end{array}$ & $\mathbf{t}$ & $\mathbf{p}$ \\
\hline $\begin{array}{l}\text { Post- } \\
\text { Test }\end{array}$ & Control & 30 & 5.07 & 1.80 & -20.44 & .001 \\
\cline { 2 - 5 } & Experimental & 30 & 13.53 & 1.38 & & \\
\hline
\end{tabular}

According to Table 4, the mean score of the post-test was found 5.07 for the control and 13.53 for the experimental group. The $p$ value was found .001 for the scores of the subjects in two groups. As $p<0.05$, the difference between the control and the experimental group was found statistically significant.

Table 5. Paired Samples T-Test Results

\begin{tabular}{|l|l|l|l|l|l|l|}
\hline Test & Group & $\mathbf{N}$ & Mean & $\begin{array}{l}\text { Std. } \\
\text { Deviation }\end{array}$ & $\mathbf{t}$ & $\mathbf{p}$ \\
\cline { 1 - 5 } Pre-Test & Experimental & 30 & 4.93 & 1.53 & 22.84 & .001 \\
\cline { 1 - 4 } & Experimental & 30 & 13.53 & 1.38 & & \\
\hline
\end{tabular}

Table 5 shows that the mean scores of the subjects in the experimental group raised from 4.93 to 13.53 following the application of the collaborative learning method. As the $p$ value is .001 , the difference between the pre- and post-test results of the experimental group was found statistically significant $(p<0.05)$.

The statistical analysis of the obtained data shows that the translation performance scores of the students who were trained with the collaborative learning method for three weeks in the experimental group increased significantly. On the other hand, the difference between the pre- and post-test results was found insignificant $(p=.738>0.05)$ for the subjects in the control group who were trained with the conventional translator training method. Accordingly, the quantitative findings of the study confirm our hypothesis by showing the statistically significant contribution of the collaborative learning method, which offers an active learning environment to translation skills, compared to the conventional translator training based on teacher-authority.

Since the main focus of the study was to investigate the improvement in the translation skills of the participants trained with the collaborative learning method, the pre- and post-test scores of the participants were compared in terms of three translation quality categories, accuracy/target language quality, terminology/culture-specific items and grammar/spelling/punctuation. Furthermore, the translations in the pre- and post-test were compared. The mean values of the three translation quality categories achieved by the experimental group in the pre-test and post-test are also presented in Table 6.

Table 6. Pre- and Post-Test Mean Values of the Experimental Group

\begin{tabular}{|l|l|l} 
Categories & Pre-Test Mean Value & Post-Test Mean Value
\end{tabular}




\begin{tabular}{|l|l|l|}
\hline $\begin{array}{l}\text { Accuracy/ Target Language } \\
\text { Quality }\end{array}$ & 1.96 & 5.00 \\
\hline $\begin{array}{l}\text { Terminology/ Culture- } \\
\text { Specific Items }\end{array} \quad 1.13$ & 3.96 \\
\hline $\begin{array}{l}\text { Grammar/ Spelling/ } \\
\text { Punctuation }\end{array}$ & 1.82 & 4.51 \\
\hline
\end{tabular}

In terms of accuracy/ target language quality, it was aimed to find out to what extent the students conveyed the ST message, achieved fluency, took into account the purpose of the ST, and acted in accordance with the textual functions of the ST and the target audience. Although the mean value of accuracy was 1.96 in the pre-test, it increased to 5.00 in the post-test.

When it comes to terminology/ culture-specific items, it was hypothesised that the training would be effective in transferring accurate terminologies in accordance with the characteristics of the text type of the TT and the target reader. The mean value of scores in terminology and culture-specific items increased from 1.13 to 3.96 after the training. For instance, although the majority of the students translated medical terms such as 'pulmonary circulation', 'capillary', 'artery', 'systol' and 'diastole' as 'pulmoner dolaşım', 'kapiller', 'arter', 'sistol', and 'diyastol' in the pre-test, respectively, in the post-test, the terminologies such as 'pharynx' and 'esophagus' were translated by the majority as 'farinks (yutak)' and 'özofagus (yemek borusu)', respectively. As observed in the translations, by taking into account the features of the source text and the requirements of the target reader, the students tended to provide both the Latin and Turkish usage of the terms after the training.

In terms of grammar/spelling/ punctuation, the mean value was increased from 1.82 to 4.51 . It is assumed that such an increase, particularly in this category of the evaluation form, stems from the structure of the applied method. The inclusion of a proofreading process in the developed collaborative learning method made it possible to fix possible errors. The improvement of each terminologist, translator and proofreader in every team in the experimental group cannot be analysed statistically as the offered method focuses on the outcome of the collaborative work as a whole rather than an individual product. However, it can be assumed that all team members improved in the aspects of the given categories since each of them got used to proofreading and editing processes, and presumably grasped the importance of such steps in a translation business.

\section{Discussion and conclusion}

It has been agreed that traditional teaching and learning methods are not sufficient alone to contributing to the skills of translators required for their professional lives. Translation business, in today's world, is in need of language experts putting multi-dimensional qualities into service along with completing mere translation tasks. Traditional training methods, on the other hand, very rarely create a platform for future translators to work and make decisions collaboratively on given translation tasks during their training process. In such methods, the 
instructor of a translation course is regarded as the only and ultimate reader and editor of the texts. Rather than these instructor-centred approaches, trainers in undergraduate translation and interpretation departments should adopt collaborative teaching methods in order to make students actively engaged in their roles as translators, authors, proof-readers, and terminologists.

This study was conducted with the aim of testing the efficacy of collaborative learning methods in translation classrooms and emphasizing the need for abandoning conventional techniques. Through preparing a new collaborative learning model to be employed in technical translation courses, it was targeted at demonstrating the benefits of this model on the translation performances of undergraduate translation students in the course of translation of medical texts.

Within the framework of the collaborative learning model developed by the researchers, students, bearing the responsibility of not only translators, but also editors, terminologists, and proof-readers, worked as a group assuming the role of a terminologist one week; a translator, the other week; and a proof-reader in the last week, contrary to the traditional methods in which students work individually. With the help of the feedback sheet (the same as translation evaluation form) developed by the researchers, they controlled another group's translation each week, all acting as proof-readers again. After three weeks, it was found with the evaluation of the post-test, that the target language quality increased significantly. In this way, they achieved equivalence and accuracy in the target culture, developed linguistic skills, and learned to use proper terminologies by taking into account the characteristics of the target genre and reader.

The obtained statistical data is believed to ascertain the unconscious and automated translation performance improvement of the participants. The statistically significant improvement in the translation competences of the students reiterate that the teaching and learning methods in undergraduate translation departments should be revised. As to trainers, they should act as translation commission initiators only, and to offer suggestions at the end of sessions if, and only if they identify inaccurate translations, thereby minimizing their role and maximizing the students'.

The present study proposes a collaborative learning method to be applied in translation pedagogy, which is confined to the second- and third-year translation students taking medical translation course. As for future attempts, we intend to make use of the fourth-year and graduate students. To test the efficacy of the model in different student groups and other translation fields, further studies are recommended to conduct the same method with larger research groups and in other technical texts, as well as non-technical translation fields such as social sciences and literary texts.

\section{References}

Al-Shehari, Khaled. 2017. Collaborative Learning: Trainee Translators Tasked to Translate Wikipedia Entries from English into Arabic. The Interpreter and Translator Trainer, 11(4), 357372. https://doi.org/10.1080/1750399X.2017.1359755 
Designing Collaborative Learning Environment in Translator Training: An Empirical Research

Barros, E. Huertas. 2011. Collaborative Learning in the Translation Classroom: Preliminary Survey Results. The Journal of Specialised Translation, 16, 42-60.

Bednar, A. K., Cunningham, D., Duffy, T. M. and Perry, J. D. 1992. Theory into Practice: How Do We Link? In T.M, Dufy and D. H, Johannson (eds.), Constructivism and the Technology of Instruction, 17-34. New Jersey: Lawrence Earlbaum Associates.

Bell, T. Roger. 1991. Translation and Translating. Theory and Practice. London and New York: Longman.

Gonzalez Davies, Maria. 2004. Multiple Voices in the Translation Classroom. Amsterdam: John Benjamins Publishing Company. https://doi.org/10.1075/btl.54

González, Marta Garcia and Veiga Díaz, María Teresa. 2015. Guided Inquiry and Project-Based Learning in the Field of Specialised Translation: A Description of Two Learning Experiences. Perspectives, 23(1), 107-123. https://doi.org/10.1080/0907676X.2014.948018

Hurtado Albir, Amparo. 1996. La enseñanza de la traducción directa 'general'. Objetivos de aprendizaje y metodología. In A. Hurtado Albir (ed.), La enseñanza de la traducción, I, 31-55. Castellón: Universitat Jaume.

Hewson, Lance. 1995. Detecting Cultural Shifts: Some Notes on Translation Assessment. In I. Mason and C. Pagnoulle (eds.), Cross-Words. Issues and Debates in Literary and Non-Literary Translating, 101-108. Liège: University of Liège

Johnson, W. David and Johnson, Roger. T. 1994. Cooperative Learning in the Classroom, Paidos, Buenos Aires.

Kiraly, Don. 1995. Pathways to Translation. Pedagogy and Process, Kent: University Press.

Kiraly, Don. 1997. Colloborative Learning in the Translation Practice Classroom. In E. Fleischmann, W. Kutz and P.A. Schmitt (eds.), Translationsdidaktik, 152-158. Germany: Tübingen.

Kiraly, Don. 2000. A Social Constructivist Approach to Translator Education: Empowerment from Theory to Practice, Manchester, St. Jerome Publishing.

Kiraly, Don. 2012. Skopos Theory Goes to Paris: Purposeful Translation and Emergent Translation Projects. MTM , 4, 119-144.

Moghaddas, Mahboubeh and Khoshsaligheh, Masood. 2019. Implementing Project-Based Learning in a Persian Translation Class: A Mixed-Methods Study. The Interpreter and Translator Trainer, 13(2), 190-209. https://doi.org/10.1080/1750399X.2018.1564542

Melnichuk, V. Marina and Osipova, Valentina M. 2017. Cooperative Learning as a Valuable Approach to Teaching Translation. XLinguae Journal, 10(1), 25-33. https://doi.org/10.18355/XL.2017.10.01.03

Neubert, Albecht. 1994. Competence in Translation: A Complex Skill, How to Study and How to Teach It. In M. Snell-Hornby, F. Pöchhacker and K. Kaindl (eds.), Translation Studies. An Interdiscipline, 411-420. Amsterdam/Philadelphia: John Benjamins. https://doi.org/10.1075/btl.2.48neu

O’Brien, Sharon. 2011. Collaborative Translation. In Y.Gambier and L. van Doorslaer (eds.), Handbook of Translation Studies, Vol. 2, 17-20. Amsterdam/Philadelphia: John Benjamins

Orozco, Mariana and Hurtado Albir, Amparo. 2002. Measuring Translation Competence Acquisition. Meta, 47( 3). 375-402. https://doi.org/10.7202/008022ar

PACTE. 2000. Acquiring Translation Competence: Hypotheses and Methodological Problems in a Research Project. In A. Beeby, D. Ensinger and M. Presas (eds.), Investigating Translation, 99106. Amsterdam: John Benjamins. https://doi.org/10.1075/btl.32.13pac

PACTE. 2003. Building a Translation Competence Model. In F. Alves (ed.), Triangulating Translation: Perspectives in Process Oriented Research, 43-66. Amsterdam/ Philadelphia: John Benjamins. https://doi.org/10.1075/btl.45.06pac

Piaget, Jean. 1954. The Construction of Reality in the Child, New York: Basic Books. https://doi.org/10.1037/11168-000

Piaget, Jean. 1955. The Language and Thought of the Child. New York: Meridian.

Piaget, Jean. 1970. Piaget's Theory. In P. H. Mussen (ed.), Carmichael's manual of child psychology, 703-730. New York: Wiley.

Piaget, Jean and Bärbel, Inhelder. 1971. Mental Imagery in the Child: A Study of the Development of Imaginal Representation. British Journal of Educational Studies, 19(3), 343-344. https://doi.org/10.2307/3120455 
Pietrzak, Paulina. 2015. Translation Competence. In Ł. Bogucki, S. Goźdź-Roszkowski, P. Stalmaszczyk (eds.), Ways to Translation, 317-338. Lodz: Lodz University Press.

Pym, Anthony. 2003. Redefining Translation Competence in an Electronic Age. In Defence of a Minimalist Approach. Meta, 48(4), 481-497. https://doi.org/10.7202/008533ar

Reiss, Katharina. 1981/2000. Type, kind and Individuality of Text: Decision Making in Translation. In L. Venuti (ed.), The Translation Studies Reader, 168-179. Oxon: Routledge.

Sorvali, Irma. 1998. The Translator as a Creative Being With Special Regard to the Translation of Literature and LSP. Babel, 44(3), 234-243. https://doi.org/10.1075/babel.44.3.04sor

Vygotsky, Lev Semenovich. 1962. Thought and Language. Cambridge: MIT Press. https://doi.org/10.1037/11193-000

Vygotsky, Lev Semenovich. 1978. Mind in Society: The Development of Higher Psychological Processes Cambridge: Harvard University Press.

Wilss, Wolfram. 1989. Towards a Multi-Facet Concept of Translation Behaviour. Target, 34, 129149. https://doi.org/10.1075/target.1.2.02wil 